\title{
RESÍDUOS DE EQUIPAMENTOS ELETROELETRÔNICOS: UM DIAGNÓSTICO DA DESTINAÇÃO NA PERCEPÇÃO DO CONSUMIDOR FINAL DE VILHENA/RO WASTE OF ELECTRO-ELECTRONIC EQUIPMENT: A DIAGNOSTIC OF THE
DESTINATION IN PERCEPTION OF THE VILHENA/RO FINAL CONSUMER
}

Wellington Silva Porto ${ }^{1}$

Ana Carolina Fontenele Brasnieski ${ }^{2}$

José Arilson de Souza ${ }^{3}$

Maurício Assuero Lima de Freitas ${ }^{4}$

\section{RESUMO}

Os Resíduos de Equipamentos Eletroeletrônicos (REEE) apresentam uma das mais elevadas taxas de crescimento do mundo, devido a crescente popularização e obsolescência programada dos equipamentos elétricos e eletrônicos. A grande preocupação frente a esse assunto é a forma de descarte desses equipamentos e os impactos que podem causar à humanidade e ao meio ambiente, devido seu alto grau de periculosidade, por possuírem em sua estrutura metais pesados altamente tóxicos, como o chumbo e o mercúrio. O consumidor final, como um dos atores da logística reversa, tem papel fundamental no fluxo reverso dos REEE, logo, o entendimento de sua percepção quanto ao descarte de REEE pode auxiliar na melhoria das políticas públicas e iniciativas privadas da implantação de um sistema de logística reversa (SLR) bem-sucedido. Este estudo tem como objetivo diagnosticar a destinação dada aos REEE pelos residentes, enquanto consumidores finais. Trata-se de uma pesquisa de campo, cujos dados foram coletados por meio de entrevistas semiestruturadas aplicadas em 100 domicílios do município de Vilhena, estado de Rondônia, Região Amazônica brasileira. Os resultados descritivos demonstraram que a maioria dos entrevistados, mesmo revelando um nível de conscientização ambiental satisfatório, não sabe como descartar seus REEE, o que acarreta no descarte para o lixo comum.

Por fim, observou-se uma assimetria informacional entre os cidadãos de Vilhena e o poder público municipal, no sentido de tornar públicos, visíveis e acessíveis os pontos de coleta de REEE implantados.

Palavras-chave: Logística reversa. REEE. Descarte. Responsabilidade Compartilhada.

Manuscript first received/Recebido em 13/03/2018 Manuscript accepted/Aprovado em: 03/12/2019

${ }^{1}$ Doutorando em Ciências Contábeis pela Universidade Federal de Pernambuco - UFPE. Mestre em Engenharia de Produção pela Universidade Federal de Santa Catarina - UFSC. Professor adjunto da Fundação Universidade Federal de Rondônia - UNIR. E-mail: wsporto@unir.br

${ }^{2}$ Bacharel em Ciências Contábeis pela Fundação Universidade Federal de Rondônia - UNIR.

${ }^{3}$ Doutor em Desenvolvimento Regional e Meio Ambiente pela Fundação Universidade Federal de Rondônia - UNIR. Docente do curso de Ciências Contábeis da Fundação Universidade Federal de Rondônia - UNIR. E-mail: professorarilson@hotmail.com

${ }^{4}$ Doutor em Economia pela Universidade Federal de Pernambuco - UFPE. Docente do Programa de Pós-Graduação em Ciências Contábeis da Universidade Federal de Pernambuco (PPGCC) da UFPE. E-mail: massuero@ig.com.br 


\section{ABSTRACT}

Waste Electrical and Electronic Equipment (WEEE) has one of the highest growth rates in the world due to the increasing popularity and scheduled obsolescence of electrical and electronic equipment. The major concern regarding this issue is the disposal of this equipment and the impacts that may cause to humanity and to the environment, due to its high degree of dangerousness, as they have in their structure highly toxic heavy metals, such as lead and mercury. Final consumers, as one of the actors in reverse logistics, play a key role in the reverse flow of WEEE, so understanding their perception of WEEE disposal can help improve public policies and private initiatives for implementing a reverse logistics system. (RLS) successful. This study aims to diagnose the destination given to WEEE by residents as final consumers. This is a field research, whose data were collected through semi-structured interviews applied in 100 households in the municipality of Vilhena, Rondônia state, brazilian Amazon Region. The descriptive results showed that most respondents, even revealing a satisfactory level of environmental awareness, do not know how to dispose their WEEE, which results in the disposal of common waste. Finally, an informational asymmetry was observed between the citizens of Vilhena and the municipal government, in order to make public the WEEE collection points implemented, visible and accessible.

Keywords: Reverse Logistics. WEEE. Discard. Shared Responsibility.

\section{INTRODUÇÃo}

É perceptível a crescente preocupação que o mundo vem desenvolvendo em relação à questão ambiental nas últimas décadas, devido ao impacto que o meio ambiente vem sofrendo com o comportamento inadequado em relação ao lixo e seu ciclo de geração e descarte. Em especial, os Resíduos de Equipamentos Eletroeletrônicos (REEE) apresentam uma das mais elevadas taxas de crescimento do mundo, devido a crescente popularização e obsolescências programada, perceptiva e funcional dos Equipamentos Elétricos e Eletrônicos (EEE).

A grande preocupação frente a esse assunto é a forma de descarte desses equipamentos e os impactos que possivelmente podem causar ao ser humano, meio ambiente, lençóis freáticos, dentre outros, por serem considerados perigosos e possuírem em sua composição metais pesados altamente tóxicos, como o chumbo e o mercúrio. O consumidor final, por vezes, desconhece tais perigos ao gerar, reter e descartar os REEE de forma inadequada (LAVEZ; SOUZA; LEITE, 2011; TANSKANEN, 2013; MARKET ANALYSIS; IDEC, 2013). Diante dessa preocupação, surge a seguinte problemática de pesquisa: qual o perfil da destinação dada aos resíduos de equipamentos eletroeletrônicos por residentes do município de Vilhena/RO?

O objetivo do estudo é diagnosticar a destinação dada aos REEE pelos residentes, enquanto consumidores finais, no município de Vilhena, localizado no cone sul do Estado de Rondônia, na Amazônia Ocidental brasileira. Para tanto, busca-se apontar aspectos legais da geração e descarte do REEE e aspectos conceituais da logística reversa; analisar quais são as consequências para o meio ambiente do descarte incorreto dos REEE; identificar o grau de conhecimento e conscientização dos cidadãos vilhenenses em relação ao descarte dos REEE; qualificar os tipos de REEE gerados no município de Vilhena; e conhecer as principais causas do descarte incorreto do REEE no município de Vilhena. 
O presente estudo contribui para a identificação do perfil de REEE gerados e dos hábitos de descarte na perspectiva do consumidor final, o qual também tem sua parcela de responsabilidade definida pela Lei $\mathrm{n}^{\mathrm{o}}$ 12.305/2010, que estabelece a Política Nacional dos Resíduos Sólidos (PNRS), onde a responsabilidade compartilhada, ali acentuada, envolve todos os atores que participam, inclusive, do ciclo de produção-distribuição-consumo-descarte de EEE. Interpretando o que a PNRS preconiza, a ABDI (2013, p. 16) entende que o papel do consumidor final na responsabilidade compartilhada pelo ciclo de vida dos EEE é o de "efetuar a devolução de seus produtos e embalagens aos comerciantes ou distribuidores após o uso".

Portanto, o escopo de pesquisa é o consumidor final do município de Vilhena/RO, que é o $3^{\circ}$ município com maior PIB do Estado de Rondônia, além de ser o $4^{\circ}$ maior município do Estado de Rondônia em população, e com $2^{\circ}$ melhor Índice de Desenvolvimento Humano (IDH) do Estado de Rondônia, ficando atrás apenas da capital do Estado, Porto Velho. E, nesse sentido, este estudo contribui como complemento de um diagnóstico mais amplo de pesquisas anteriores (ARAÚJO, 2013; FERNANDES, 2016; ABDI, 2013) e vindouras, onde cada componente da cadeia de responsabilidade compartilhada precisa ser estudado, a fim de se obter um quadro completo da situação dos REEE em municípios brasileiros, em especial, na região da Amazônia Ocidental. Ademais, o presente estudo surge como um dos pioneiros no Estado de Rondônia, no que tange à ótica do consumidor final, pois não há estudos anteriores naquele Estado que tenham traçado tal diagnóstico de retenção e descarte de REEE. Naquela mesma região, outros estudos realizados tiveram foco em outros atores da cadeia, como as empresas de assistência técnicas especializadas em equipamentos eletroeletrônicos (APPELT et al., 2015; PORTO et al., 2018).

$\mathrm{O}$ artigo está dividido em quatro seções. A primeira seção apresenta aspectos teóricos, estruturais e legais relacionados à questão ambiental e aos resíduos de equipamentos eletroeletrônicos. A segunda seção descreve a metodologia da pesquisa. A terceira seção aborda os resultados obtidos com a pesquisa de campo. A quarta seção traz as considerações finais e as perspectivas para pesquisas futuras.

\section{A GERAÇÃO DE RESÍDUOS DE EQUIPAMENTOS ELETROELETRÔNICOS: UMA QUES- TÃO AMBIENTAL E DE SAÚDE PÚBLICA}

Pela diretiva 19/2012 da União Europeia, equipamentos eletroeletrônicos (EEE):

[...] são todos os equipamentos dependentes de corrente elétrica ou de campos eletromagnéticos para funcionarem corretamente, bem como os equipamentos para geração, transferência e medição dessas correntes e campos, e concebidos para utilização com uma tensão nominal não superior a $1.000 \mathrm{~V}$ para corrente alternada e $1.500 \mathrm{~V}$ para corrente contínua (UE, 2012, p. 6).

Esses equipamentos estão cada vez mais introduzidos no cotidiano das pessoas, e estão associados à escalabilidade e potencial de inovação, os quais crescem com uma velocidade tecnológica cada vez maior, e com praticamente o mesmo custo.

Especialmente a partir da década de 50, os produtos eletrônicos, objeto de desejo da grande maioria da população mundial, diante da rapidez com que avança a tecnologia, são fabricados com previsão de vida útil cada vez menor. Em outras palavras, eles têm data marcada para "morrer", em função das chamadas obsolescências programada, perceptiva e funcional. Esta surge como uma 
estratégia de aceleração do consumo que passa a ser o principal causador da degradação ambiental. Tal degradação se estende desde o uso da matéria-prima, gastos com energia, água, produtos químicos e demais insumos durante o processo de fabricação, segue pela comercialização, até o descarte dos produtos e suas embalagens (LEONARD, 2011; 2017).

Ao mesmo tempo, existe uma carência generalizada de locais apropriados para a destinação desses equipamentos, que, em desuso, vão gerar os chamados resíduos de equipamentos eletroeletrônicos (REEE). Quando os REEE são dispostos de forma inadequada, ou ainda, quando desmontados sem controle, podem ocasionar impactos ambientais negativos, através da contaminação do solo, das águas superficiais e subterrâneas, representando risco à saúde da população do entorno ou dos trabalhadores que fazem a desmontagem (WIDMER et al., 2005).

Xavier e Carvalho (2014, p. 2) complementa o conceito de REEE ressaltando que "são aqueles produtos, partes ou componentes de EEE pós-consumo". Seguindo a mesma linha de raciocínio, nos estudos de Baldé et al. (2017), os REEE referem-se a todos os itens de um EEE e/ou suas partes, que tenham sido descartados por seu proprietário sem a intenção de reuso. Significa que os EEE se tornam resíduos quando o equipamento se torna obsoleto ou apresenta algum tipo de problema, e, por consequência, o consumidor não tem mais suas expectativas atendidas, efetuando assim o descarte, o qual ocorre, na maioria das vezes, inadequadamente.

Nos relatos de El Faro, Calia e Pavan (2013), há uma comparação do crescimento do lixo comum com o REEE, no qual, o segundo se destaca crescendo três vezes mais rápido que o primeiro. Tal crescimento acelerado e exagerado se apresenta como um alerta em escala mundial, com efeitos prognósticos negativos para a natureza. Estudos mais recentes mostram que em 2016 foram gerados 44,7 milhões de toneladas de resíduo de equipamento eletroeletrônico no mundo (BALDÉ et al., 2017), conforme pode ser visualizado resumidamente na Figura 1.

Figura 1 - REEE global gerado e estimativas até 2021.

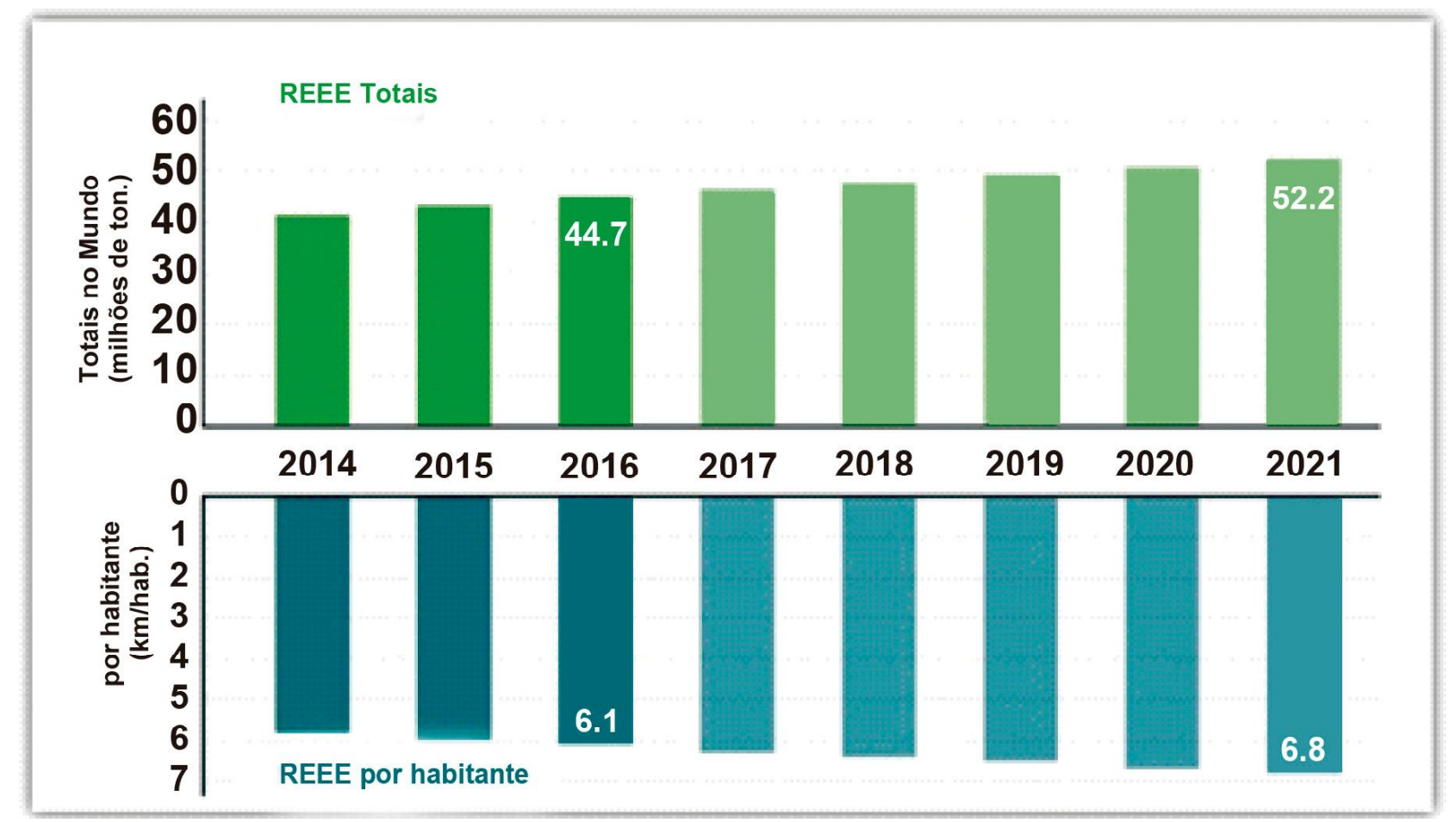

Fonte: Baldé et al. (2017). Tradução livre. 
O que se vê é o aumento descomedido na geração dos REEE ao final de sua vida útil (XAVIER; CARVALHO, 2014; LU; LIU; YANG, 2015; CAO et al., 2016; FLYGANSVAER; DAHLSTROM; NYGAARD, 2018). Na verdade, é possível notar que o REEE é um dos principais símbolos do antropoceno, ao mesmo tempo em que se percebe que, esse mesmo REEE parece, muitas vezes, negligenciado entre os problemas ambientais prioritários, abordados nas recentes políticas públicas e empresariais de redução de impactos ambientais ao redor do mundo. Nesse sentido, a transição para um ambiente mais limpo precisa estar fundamentada em ações capazes de mitigar o acúmulo de resíduos e rejeitos sólidos, nos quais se incluem os REEE, onde os próprios resíduos possuam bastante valor agregado (LUZ, 2017).

Observando o contexto brasileiro, de acordo com a ABDI (2013), estimou-se que no Brasil a geração de REEE em 2016 seria de 1.376,13 kilotoneladas. Entretanto, na apuração de Baldé et al. (2017), o Brasil ultrapassou as estimativas da ABDI, gerando 1.534 kilotoneladas de REEE naquele ano, compondo uma média de 7,4 kg por habitante. Estima-se ainda que a taxa de crescimento da geração de REEE até 2020 será de 3\% a 5\% a.a. (XAVIER; CARVALHO, 2014; RODRIGUES; GUNTHER; BOSCOV, 2015; BALDÉ et al., 2017; FORTI; BALDÉ; KUEHR, 2018).

Entre as substâncias mais presentes, ou resultantes do uso de equipamentos eletroeletrônicos, e de maior impacto à saúde humana e ao meio ambiente, estão os metais pesados, CloroFluorCarbonetos (CFC), as substâncias halogenadas, bifenilas policloradas, arsênio, bromatos e os retardantes de chama Bifenilas Polibromadas e Éteres Difenílicos PoliBromados (XAVIER; CARVALHO, 2014). Portanto, ao mesmo tempo que a evolução tecnológica vem crescendo de forma incessante, por outro lado, essa tecnologia pode resultar em grandes prejuízos para a saúde humana, principalmente no que se refere a forma de tratamento e descarte desses materiais tóxicos. O contato e a absorção dessas substâncias tóxicas podem causar agravos aos seres humanos. Mesmo a incineração, vista por alguns como solução para a questão dos REEE, tem consequências negativas para o meio ambiente e a vida.

Em maio de 2001, o Brasil assinou a Convenção de Estocolmo, tratado da Organização das Nações Unidas (ONU), que aborda o combate aos Poluentes Orgânicos Persistentes (POPs), e que aponta a incineração de resíduos como uma das principais fontes geradoras destes poluentes, e recomenda que o uso de incineradores seja eliminado progressivamente. Um exemplo disso é a carcaça dos EEE, que, em sua maioria, contém plástico em sua estrutura, a qual é triturada e separada conforme a sua densidade; depois o material é vendido para empresas que utilizam os polímeros presentes nesses objetos, ou são derretidos e transformados em outros plásticos. Entretanto, esses resíduos também são incinerados para a geração de energia, provocando discussões sobre as substâncias geradas através da incineração, tal como a dioxina, substância que se acumula no organismo, mesmo em pequenas quantidades, prejudicando a formação de fetos durante a gravidez, por ser teratógena, além de ser comprovadamente cancerígena (GREENPEACE, 2017).

Em função da presença de alguns componentes tóxicos, o manejo dos REEE precisa ser específico e bem gerenciado. Alguns dos materiais podem ser reciclados e recuperados, contudo, podem prejudicar as pessoas quando manuseados incorretamente (VAISHNAV; DIWAN, 2013) ou afetar o meio ambiente através de contaminação das águas e lençóis freáticos por possuírem substâncias como chumbo, cádmio e mercúrio (ROBINSON, 2009; PEREIRA; FERRAZ; MASSAINI, 2014; XAVIER; CARVALHO, 2014; LU; LIU; YANG, 2015; CAO et al., 2016; FLYGANSVAER; DAHLSTROM; NYGAARD, 2018). Logo, os materiais que não são mais adequados para serem reutilizados para o mesmo fim, são desmontados, e a carcaça, a bateria, o vidro e as placas de circuito são separados, sendo dado um destino diferente para cada componente. 
Entretanto, o manuseio inadequado e a exposição às substâncias tóxicas por cooperativas de catadores, são apontados nos estudos de Souza (2015) como causa para diversas doenças relacionadas ao sistema respiratório e doenças crônicas não transmissíveis. A pesquisadora alerta para o risco à saúde humana quando catadores e separadores são expostos às substâncias presentes nos REEE, e recomenda ações de "monitoramento desse tipo de trabalho, considerando-se que a literatura internacional menciona risco de contaminação e a literatura nacional reconhece a fragilidade dos catadores de material reciclável em relação à saúde, dada sua situação de vulnerabilidade social".

\section{A QUESTÃO LEGAL DA LOGÍSTICA REVERSA E DOS REEE NO BRASIL}

No Brasil, após 21 anos de tramitação no Congresso Nacional, foi promulgada, em 2010, a Lei n. ${ }^{\circ} 12.305$, que institui a Política Nacional dos Resíduos Sólidos (PNRS), regulamentada pelo decreto de

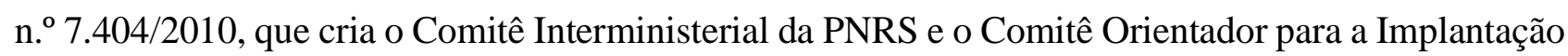
dos Sistemas de Logística Reversa, com o objetivo de promover o gerenciamento ambiental adequado dos resíduos sólidos, de forma isolada, pelo Governo Federal, ou, em regime de cooperação entre Estados, Distrito Federal, Municípios ou inciativa privada (BRASIL, 2010a; 2010b).

Após o início da vigência da PNRS, os autores Silva, Balbino e Gómez (2011) manifestaram seu entendimento de que o Estado, pelas atribuições que lhe são conferidas, tem o papel de regular e de fiscalizar as atividades que se desviam do desenvolvimento sustentável, além de fomentar a elaboração de alternativas capazes de tornar mais coerentes as ações humanas quanto ao meio ambiente. Na visão dos autores, é mister a participação de terceiros para atender as demandas da sociedade, não sendo uma tarefa só do Estado. Seu discurso destaca o papel da cidadania, onde o indivíduo e as instituições públicas, privadas e do terceiro setor devem se unir para minimizar os problemas, esclarecendo que é uma obrigação mútua buscar melhorias sociais.

A PNRS também define um importante instrumento capaz de contribuir para o desenvolvimento econômico e social na questão dos resíduos sólidos: a logística reversa (LR). O termo "logística" sofreu uma evolução em sua acepção. Em sua origem grega, o termo era usado para definir a atividade de distribuição física e financeira dos impérios Romano, Grego e Bizantino, usando razão e lógica em sua execução. Com o passar dos séculos, uma conotação militar foi implementada à atividade logística, relacionando-a a obtenção, manutenção e transporte de materiais, pessoal e instalações. Somente após a Segunda Guerra Mundial é que o termo passou a ser relacionado à atividade empresarial, ganhando relevância e evoluindo em seus desmembramentos conceituais. E o que até então direcionava a racionalidade dos processos logísticos em um canal de fluxo direto, também passa a ser considerado como um canal de fluxos reversos (BARTHOLOMEU; CAIXETA-FILHO, 2011).

Leite (2019a) define logística reversa como:

[...] a área da logística empresarial que planeja, opera e controla o fluxo físico, e as informações correspondentes, do retorno ao ciclo de negócios ou produtivo de produtos de pós-venda (não consumidos) e de pós-consumo (consumidos), através dos diversos canais de distribuição reversos agregandolhes valor de diversas naturezas: econômico, legal, de prestação de serviços, de correção de falhas operacionais, de imagem corporativa, entre outros. 
Os canais de distribuição reversos seguem duas vertentes: pós-consumo e pós-venda. Essas vertentes podem ser visualizadas na Figura 2.

Figura 2 - Logística reversa e suas duas vertentes.

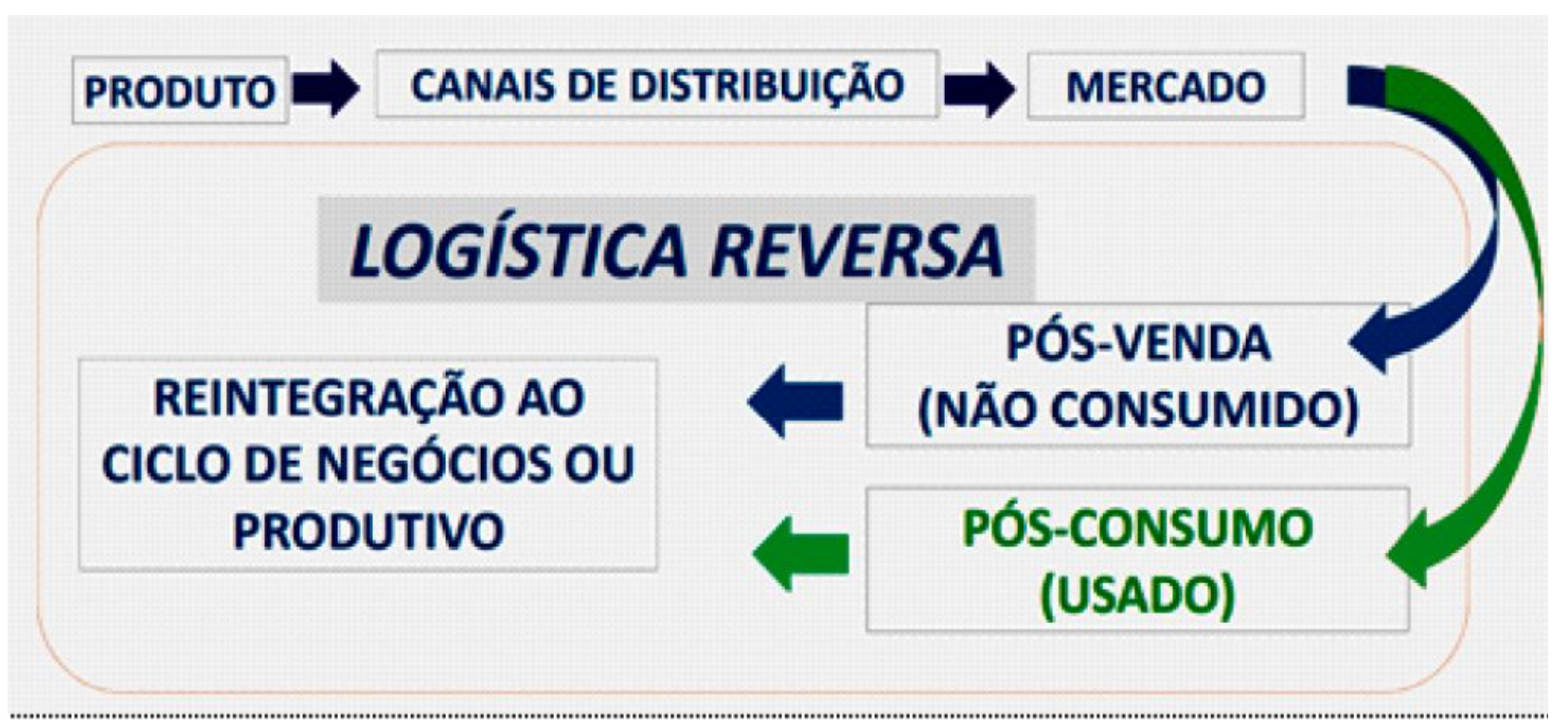

Fonte: Leite (2019b)

Leite (2017) classifica que a primeira vertente está direcionada para os produtos com pouco ou nenhum uso, que seguem num fluxo reverso motivados por problemas de qualidade ou processos comerciais; ao passo que, a segunda vertente está direcionada a uma parcela de produtos originalmente descartados, em função da finalização de sua utilidade, e que retornam ao ciclo produtivo de alguma forma. Os canais de distribuição reversos pós-venda ainda se subdividem em subcanais reversos de reciclagem e subcanais reversos de reuso.

Seja qual for a categoria de LR, dois fatores são determinantes para a destinação ser uma realidade em qualquer dos canais reversos: incentivos econômicos e imposições legais (BARTHOLOMEU; CAIXETA-FILHO, 2011).

A PNRS traz em seu Artigo 33, Inciso IV, a obrigatoriedade dos fabricantes, importadores, distribuidores e comerciantes de produtos eletroeletrônicos implementarem sistemas de logística reversa (BRASIL, 2010a). Dessa forma, todo o material produzido por essas empresas deve ser recolhido pelas mesmas após o uso pelo consumidor. E esse processo independe do serviço público de limpeza urbana e de manejo dos resíduos sólidos, segundo o citado artigo.

No que tange aos REEE, para a LR se tornar uma realidade no Brasil, é preciso o fechamento de um acordo setorial para definir implantação de um sistema de logística reversa (SRL) de produtos eletroeletrônicos e seus componentes. O Ministério do Meio Ambiente (MMA) avançou em direção a concretização de um acordo setorial, ao abrir consulta pública para contribuições e sugestões sobre a proposta de acordo setorial para implantação do SLR para REEE, com prazo de encerramento em 30 de agosto de 2019 (BRASIL, 2019). A proposta tem, até o momento, como partes integrantes, o MMA, a Associação Brasileira da Indústria Elétrica e Eletrônica (ABINEE), a Associação Nacional dos Fabricantes de Produtos Eletroeletrônicos (ELETROS), a Associação Brasileira dos Distribuidores de Produtos e Serviços de Tecnologia da Informação (ABRADISTI), a Federação das Associações das Empresas Brasileiras de Tecnologia da Informação (ASSESPRO NACIONAL); e como intervenientes 
anuentes, a Confederação Nacional do Comércio de Bens, Serviços e Turismo (CNC), a Associação Brasileira de Reciclagem de Eletroeletrônicos e Eletrodomésticos (ABREE), e a Gestora de Resíduos Eletroeletrônicos Nacional (GREEN ELETRON).

$\mathrm{O}$ acordo prevê obrigações para os fabricantes, importadores, distribuidores e comerciantes e sua implementação se dará em duas fases. A primeira compreenderá ações como a adesão das empresas à entidade gestora, a instituição de mecanismo financeiro para assegurar a sustentabilidade econômica do sistema, a aprovação de medidas fiscais de simplificação da operacionalização da LR, com isenção de impostos, e o reconhecimento da não periculosidade dos equipamentos em fim de vida. Já a segunda fase, estará focada na habilitação de prestadores de serviços para atuar no sistema, na elaboração de plano de comunicação e de educação ambiental não formal, assim como na instalação de pontos de recebimento e/ou de consolidação.

A expectativa é que o SLR para REEE seja implantado no prazo de cinco anos e resulte na destinação ambientalmente adequada de $17 \%$, em peso, dos produtos eletroeletrônicos comercializados no mercado interno. A proposta de acordo setorial deixa implícita a responsabilidade do consumidor, baseada no conceito de responsabilidade compartilhada, que deverá ser orientado pelos comerciantes, quanto à destinação de seus REEE até o ponto de recebimento.

\section{A RESPONSABILIDADE COMPARTILHADA}

A responsabilidade compartilhada é instituída no artigo 30 da PNRS, que prevê a elaboração do Plano Nacional de Resíduos Sólidos e significa que a responsabilidade não é apenas do setor público, mas de todos aqueles envolvidos no ciclo produtivo, como: indústria, fornecedor, governo e consumidor final, conforme mostrado na Figura 3. Segundo a PNRS, em seu art. $3^{\circ}$, XVII, a responsabilidade compartilhada pelo ciclo de vida dos produtos é um

[...] conjunto de atribuições individualizadas e encadeadas dos fabricantes, importadores, distribuidores e comerciantes, dos consumidores e dos titulares dos serviços públicos de limpeza urbana e de manejo dos resíduos sólidos, para minimizar o volume de resíduos sólidos e rejeitos gerados, bem como para reduzir os impactos causados à saúde humana e à qualidade ambiental decorrentes do ciclo de vida dos produtos, nos termos desta Lei (BRASIL, 2010a, grifo nosso).

Com vistas a fortalecer essa responsabilidade compartilhada, os fabricantes, importadores, distribuidores e comerciantes têm como principal responsabilidade o recolhimento dos produtos e dos resíduos remanescentes após o uso, assim como sua subsequente destinação final ambientalmente adequada (art. 31, PNRS), e no caso de produtos objeto de SLR, ficam obrigados, na forma do art. 33, inc. VI, mediante retorno dos produtos eletroeletrônicos e seus componentes após o uso pelo consumidor final, de forma independente do serviço público de limpeza urbana e de manejo de resíduos sólidos. (BRASIL, 2010a)

De acordo com a PNRS, são juridicamente responsáveis pela LR de um produto todos aqueles que participam do seu ciclo de vida, que se inicia com o desenvolvimento e fabricação do produto, e vão até a destinação adequada do resíduo do produto ou da embalagem, ou, eventualmente, até a disposição final ambientalmente adequada dos seus rejeitos, e, nesse caso, os consumidores finais integram, com papel relevante, a cadeia de atores da LR (XAVIER; CARVALHO, 2014). 
Figura 3 - Ciclo da Logística Reversa segundo a PNRS.

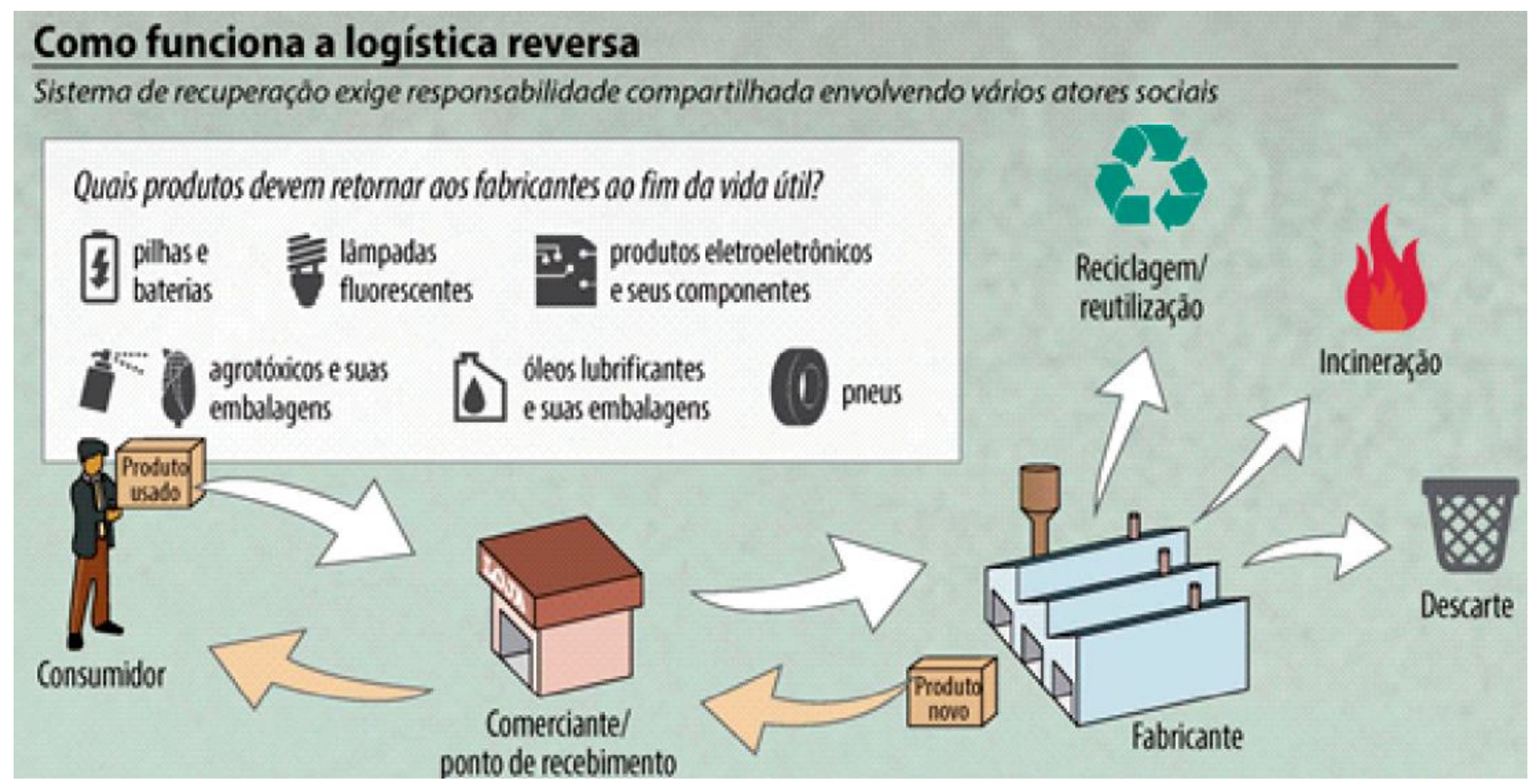

Fonte: Senado Federal (2014)

Nesse fluxo reverso, que abrange múltiplos atores, com diferentes papéis na estruturação de uma rede para a LR, é possível prospectar um cenário de "inovações disruptivas", como a mineração urbana, vista como alternativa de obtenção de recursos, aproveitando, economicamente, matériaprima secundária (XAVIER; LINS, 2018), ou o mercado de créditos da logística reversa descrito por Caiado et al. (2017). Nos exemplos citados, bem como nos textos da PNRS do Decreto 7.404/2010 e da proposta de acordo setorial do MMA (BRASIL, 2010a; 2010b; 2019), o papel de conscientização do consumidor é destacado como sendo essencial para um SLR bem-sucedido, como na pesquisa de Pereira, Ferraz e Massaini (2014).

\section{MÉTODO}

A presente pesquisa de campo se caracteriza como exploratória e descritiva, por proporcionar maior familiaridade com o problema, com vistas a torná-lo mais explícito ou a constituir hipóteses. Neste estudo, a familiaridade com o problema de pesquisa se deu em função de discutir seus fundamentos e contextualizações, bem como ao explicitá-lo com a exposição da situação de destinação de REEE e conscientização do consumidor final no processo de LR. Seu planejamento é, portanto, flexível, possibilitando a consideração dos mais variados aspectos relativos ao fato estudado. As pesquisas de campo descritivas têm como objetivo primordial a descrição das características de determinada população ou fenômeno, ou, o estudo de relações entre variáveis, e sua ferramenta dominante é a entrevista (SMITH, 2003).

O campo de pesquisa escolhido foi o município de Vilhena/RO (Figura 4). Sua população estimada de acordo com o IBGE (2018) é de 97.448 habitantes, sendo assim, a $4^{\text {a }}$ cidade mais populosa do estado de Rondônia e a $33^{\mathrm{a}}$ mais populosa da Região Norte do Brasil. A cidade possui também o $2^{\circ}$ melhor IDH do estado de Rondônia e o $13^{\circ}$ melhor da Região Norte do Brasil. Vilhena é conhecida como Portal da Amazônia Ocidental, por estar localizada em uma das entradas da Amazônia Ocidental, 
e também é conhecida como Cidade Clima da Amazônia, por sua temperatura ser menor, quando comparada a outras cidades da Região Norte.

Figura 4 - Município de Vilhena em destaque.

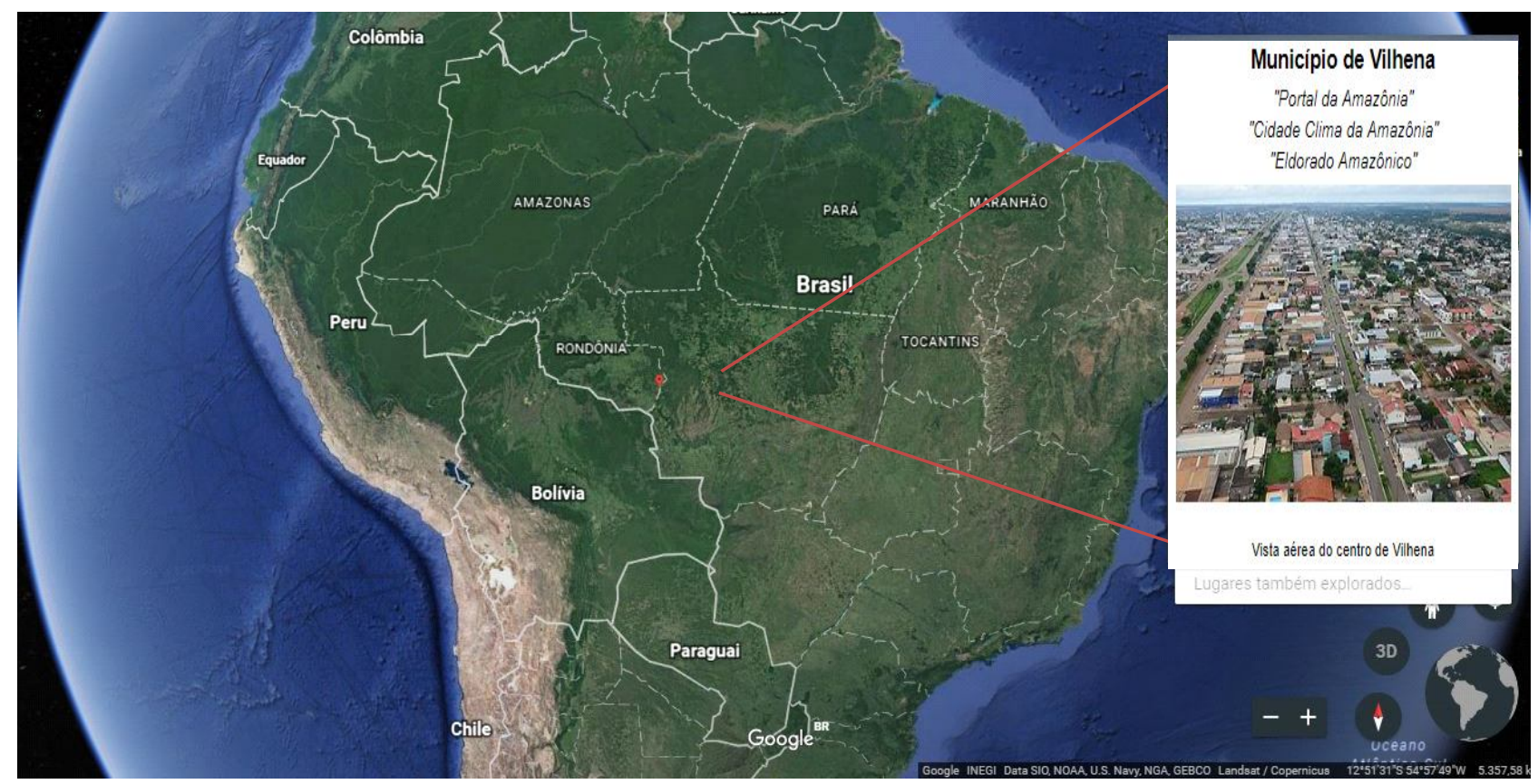

Fonte: Adaptado do Google Earth (2017)

No município de Vilhena, a autarquia de Serviço Autônomo de Água e Esgoto (SAAE) juntamente com a prefeitura do município teve como iniciativa a elaboração do Plano Municipal de Gestão Integrada de Resíduos Sólidos de Vilhena (PLAMRESOLV), sendo concedido segundo o disposto na PNRS e na Lei Federal no 11.445 de 05 de janeiro de 2007 (BRASIL, 2007), que estabelece a Política Nacional de Saneamento Básico, visando satisfazer os requisitos necessários para que a Prefeitura cumpra com suas responsabilidade e obrigações na condição de titular dos serviços públicos de saneamento básico do Município. O PLAMRESOLV implantou três Pontos de Entrega Voluntária (PEV), que ficam localizados nas praças do município, onde os consumidores finais de Vilhena podem descartar seus resíduos Eletroeletrônicos sem quaisquer ônus. Essa iniciativa teve início no dia 24 de março de 2017.

Quanto à forma de abordagem, a pesquisa se caracteriza pelo uso de estatística descritiva, onde os dados da pesquisa de campo foram obtidos a partir de entrevistas semiestruturadas junto aos proprietários das residências do município de Vilhena/RO.

A amostra foi obtida a partir da aplicação da fórmula (1),

$$
\frac{\frac{=^{2} \mathrm{x} p(1-p)}{e^{2}}}{1+\left(\frac{=^{2} \mathrm{x} p(1-p)}{e^{2} N}\right)}
$$

Onde, $N$, é o tamanho da população, que segundo IBGE (2018) é de 97.448 habitantes, $e$, é a margem de erro, a qual foi de $10 \%$, $z$, é o nível de confiança, de $95 \%, p$, é a proporção de interesse, que nesse caso, foi adotado como sendo de 50\%, seguindo os parâmetros adotados por Rodrigues, 
Gunther e Boscov (2015), o que resultou numa amostra de 96 residências. Considerando-se uma taxa de resposta de $95 \%$, por eventuais motivos de ausência de respondente na residência, ou, por recusa em participar da pesquisa, e utilizando-se a fórmula (2), optou-se por arredondar a amostra para 100 residências.

$$
\frac{N^{o} \text { de respondentes necessários }}{\% \text { de respostas esperadas }} \quad \times 100
$$

Portanto, no período de janeiro a março de 2017, foram realizadas visitas e entrevistas em 100 (cem) residências, nos bairros mais populosos da cidade, em virtude de representarem satisfatoriamente o perfil de consumo de REEE da população. Os bairros não incluídos na pesquisa são formados por loteamentos recém-constituídos e que ainda contam com número inexpressivo de habitantes.

Os formulários foram estruturados com questões de fácil entendimento, elaborados com linguagem acessível aos respondentes, aplicados e respondidos na presença do pesquisador, estando este pronto a esclarecer eventuais dúvidas, com o intuito de garantir a compreensão do tema pesquisado. Além das perguntas relacionadas a geração, retenção e descarte do REEE, foram aplicadas questões referentes ao grau de conhecimento sobre as consequências e impactos que podem ser causados à saúde humana e ao meio ambiente por conta do manuseio e descarte incorreto dos REEE.

\section{RESULTADOS OBTIDOS}

Neste tópico, serão apresentados os resultados da pesquisa de campo aplicada.

\subsection{PERFIL DA DESTINAÇÃO DOS REEE EM VILHENA/RO}

Inicialmente, percebe-se na Tabela 1 que aproximadamente dois terços dos respondentes retêm seus REEE em suas residências, superando os resultados obtidos no estudo do Market Analysis e IDEC (2013). As impressões colhidas nas entrevistas revelam que essa é uma prática aprendida com os descendentes, uma vez que, mesmo sem a utilização original, os REEE são vistos como equipamentos que podem ter suas partes adaptadas e reutilizadas em algum momento da vida dos residentes, fato que na maioria das vezes não se consuma, e os REEE seguem se acumulando e liberando toxinas, como relatado por Leonard (2017).

Tabela 1 - Equipamentos eletroeletrônicos guardados sem utilização.

\begin{tabular}{c|c}
\hline RESPOSTA & $\%$ \\
\hline Guardo equipamentos eletroeletrônicos sem utilização & 68 \\
\hline Não guardo equipamentos eletroeletrônicos sem utilização & 32 \\
\hline
\end{tabular}

Fonte: Dados da pesquisa.

Na Figura 5, que mostra os REEE gerados, os respondentes que residem em bairros nobres, como Centro, São José, Cidade Nova, Alto Alegre, Green Ville e Jardim Social, mostram uma disposição maior em reter REEE. Isso se deve ao alto padrão de consumo revelado pelos respondentes, os quais costumam ceder à obsolescência programada, fazendo-os trocar constantemente seus EEE, ratificando a tendência alertada por Leonard $(2011 ; 2017)$. 
Figura 5 - Equipamentos eletroeletrônicos residenciais sem utilização (sem funcionar ou obsoletos)

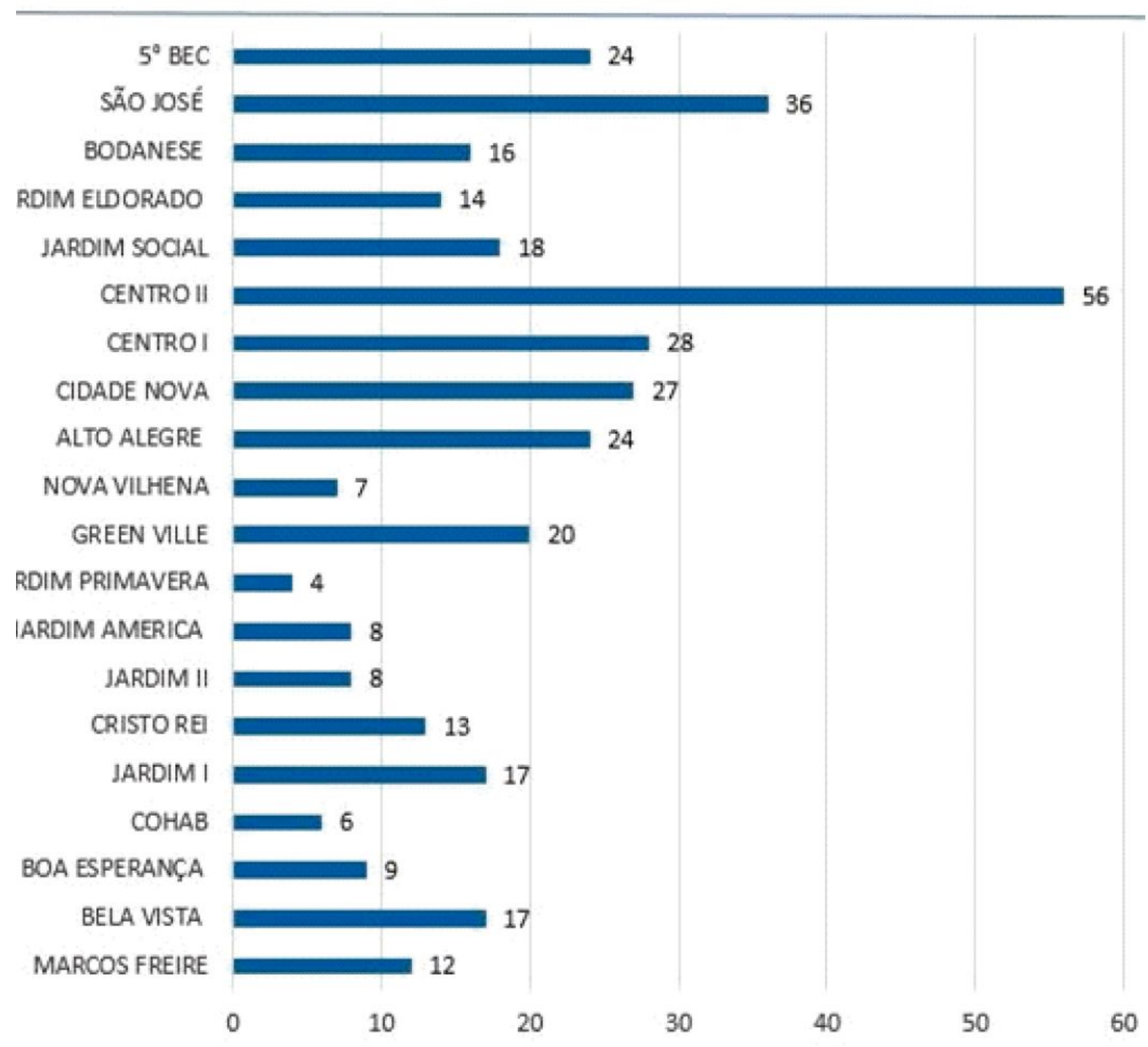


Figura 6 - Descrição dos equipamentos

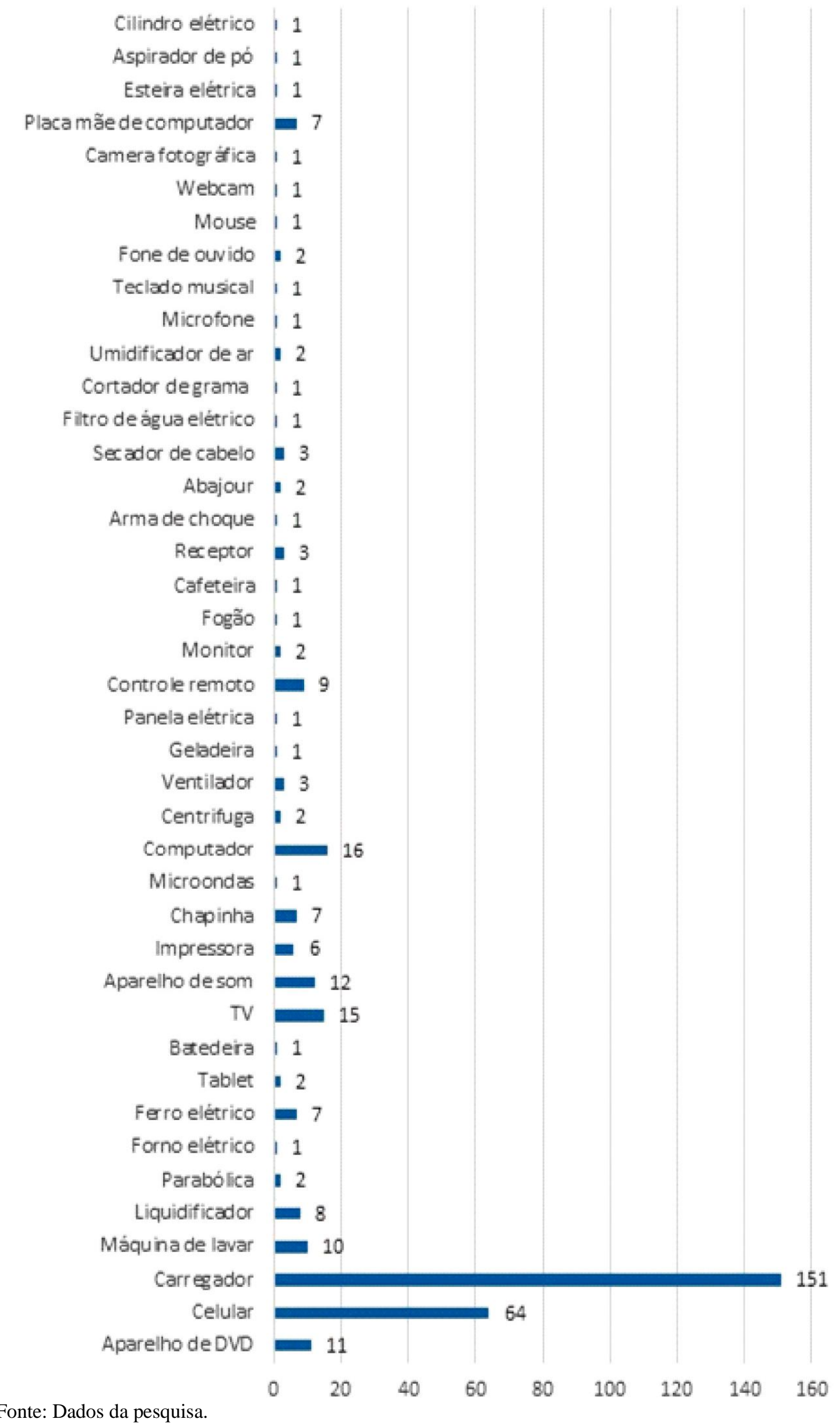


Entre os REEE gerados, destacam-se, como visto na Figura 6, os carregadores e celulares, confirmando os resultados de Rodrigues, Gunther e Boscov (2015), onde a maior número de REEE para a cidade de São Paulo também são os aparelhos celulares, e corroborando a previsão da ABDI (2013), onde, do volume esperado para 2017 e 2018, quase 70\% dos REEE gerados seriam de pequeno porte, bem como a estimativa de Baldé et al. (2017) de geração de 16,8 milhões de toneladas de REEE de pequeno porte no mundo para 2016, representando 37,6\% do total de REEE.

Quanto ao nível de conscientização sobre a responsabilidade compartilhada no ciclo pósconsumo, os respondentes, na ordem de aproximadamente 90\%, compreendem seu papel na logística reversa (Tabela 2), uma vez que demonstram conhecer a importância de cumprir com suas obrigações de preservação do meio ambiente, quanto ao descarte correto dos REEE. Entretanto, a conscientização é apenas um dos passos iniciais para a prática responsável de descarte, conforme explica Pereira, Ferraz e Massaini (2014), quando procuraram descrever as dimensões da consciência de consumidores na reciclagem dos REEE em relação às práticas realizadas efetivamente.

Tabela 2 - Conscientização sobre o descarte dos REEE.

\begin{tabular}{l|c}
\hline \multicolumn{1}{c|}{ RESPOSTA } & $\%$ \\
\hline Sei que os REEE devem ser descartados de forma diferente dos demais tipos de lixo. & 89 \\
\hline Não sabia que os REEE devem ser descartados de forma diferente dos demais tipos de lixo. & 11 \\
\hline
\end{tabular}

Fonte: Dados da pesquisa.

A Tabela 3 reforça a conscientização revelada na Tabela 2, porém, nota-se que uma boa parcela dos respondentes que entendem que devem descartar os REEE de forma diferenciada em relação ao lixo comum, desconhecem os riscos do descarte incorreto. O resultado coaduna com os resultados de Pereira, Ferraz e Massaini (2014), que mostraram que a população está consciente acerca dos REEE, que compreende de diferentes formas, e que, embora a contribuição seja vista como medida socialmente aceita, é pouco praticada devido ao desconhecimento dos riscos inerentes ao descarte incorreto dos REEE, os quais foram descritos nos estudos de Vaishnav e Diwan (2013) e de Souza (2015).

Tabela 3 - Conscientização sobre o risco do descarte incorreto dos REEE.

\begin{tabular}{l|c}
\hline \multicolumn{1}{c|}{ RESPOSTA } & $\%$ \\
\hline Sei dos riscos que o descarte incorreto dos REEE causa ao meio ambiente e à saúde humana. & 55 \\
\hline $\begin{array}{l}\text { Não sei dos riscos que o descarte incorreto dos REEE causa ao meio ambiente e à saúde } \\
\text { humana. }\end{array}$ & 45 \\
\hline
\end{tabular}

Fonte: Dados da pesquisa.

Ressalta-se que, durante as entrevistas, todos os respondentes manifestaram que acham importante que a sociedade de maneira geral descarte os REEE de maneira correta. Percebe-se nessa opinião que, embora alguns não saibam de suas obrigações ou dos riscos do descarte incorreto dos REEE, há uma conscientização implícita sobre a responsabilidade compartilhada expressa na PNRS (BRASIL, 2010), além do indício da ocorrência de uma assimetria informacional, a qual pode ser reduzida com políticas públicas voltadas a priorizar a ampla divulgação de orientações sobre o descarte de REEE aos seus munícipes. 
Figura 7 - Formas de descarte utilizadas pelos respondentes (em \%).

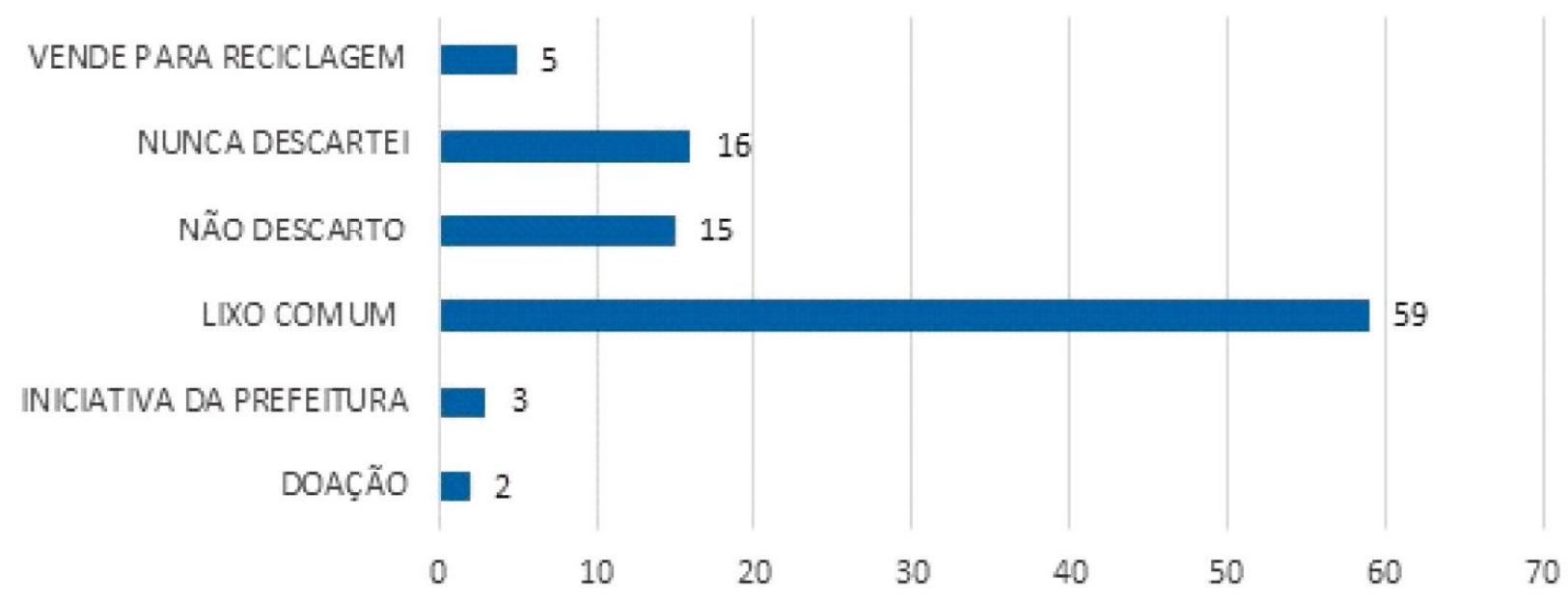

Fonte: Dados da pesquisa.

A carência de uma educação ambiental voltada para o descarte correto de REEE é demonstrada na Figura 7, na qual os respondentes revelam que em sua maioria descartam os REEE de maneira incorreta, sendo a maior parte descartada junto ao lixo comum. Apenas $10 \%$ dos respondentes procuram descartar de forma correta (venda, doação ou prefeitura), o que reforça a postura de inércia detectada por Araújo (2013) e Pereira, Ferraz e Massaini (2014).

A ausência quase total de conscientização da prática correta de descarte dos REEE entre os respondentes, conforme mostrado na Tabela 4, confirma novamente o paradoxo entre consciência ambiental e prática ambiental descrita por Pereira, Ferraz e Massaini (2014), e as percepções in loco revelaram como causas, o desconhecimento de iniciativas, como a da prefeitura, com o PLAMRESOLV, e a não percepção de que os comerciantes e distribuidores dos EEE figuram como alternativa de entrega dos REEE, o que refletiria na adequação ao contexto da responsabilidade compartilhada estabelecida pela PNRS (BRASIL, 2010).

Tabela 4 - Conscientização sobre a logística reversa dos REEE.

\begin{tabular}{l|c}
\hline \multicolumn{1}{c|}{ RESPOSTA } & $\%$ \\
\hline Sei que devo devolver os REEE aos comerciantes ou distribuidores após o uso. & 17 \\
\hline Não sabia que devo devolver os REEE aos comerciantes ou distribuidores após o uso. & 83 \\
\hline
\end{tabular}

Fonte: Dados da pesquisa.

Figura 8 - Conhecimento de ponto de coleta pelos respondentes (em \%).
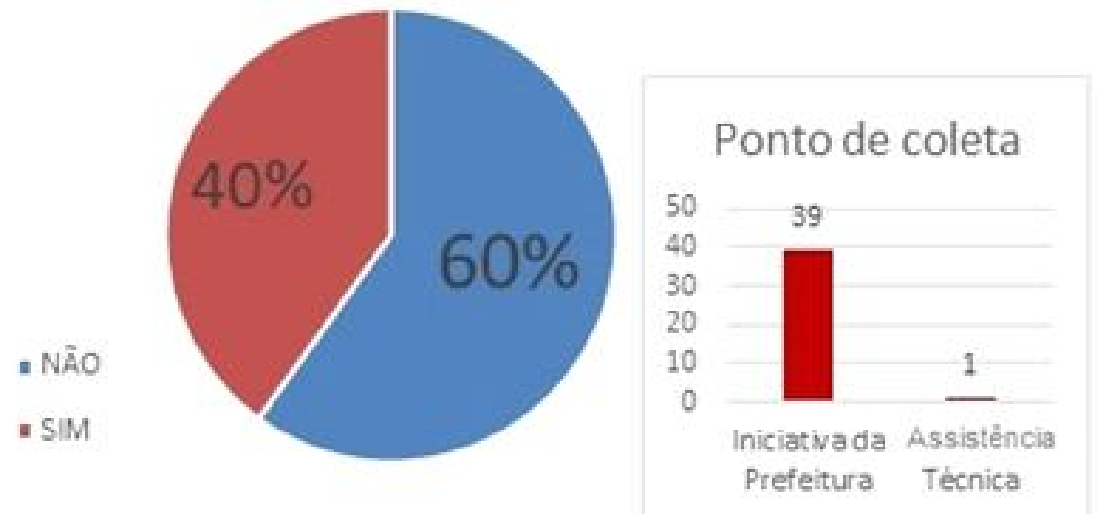

Fonte: Dados da pesquisa. 
A Figura 8 mostra que os respondentes, em sua maioria, não conhecem nenhum ponto de coleta de REEE na cidade, o que reforça a ausência de uma ampla divulgação das recentes políticas públicas implementadas pela prefeitura (PLAMRESOLV). Por outro lado, percebe-se que a maioria dos respondentes que disseram conhecer pontos de coleta de REEE, se referiram apenas aos pontos de coleta relacionados ao PLAMRESOLV, reforçando o desconhecimento da logística reversa a partir da devolução aos comerciantes e distribuidores de EEE.

Tabela 5 - Disposição para o descarte correto dos REEE.

\begin{tabular}{l|c}
\hline \multicolumn{1}{c|}{ RESPOSTA } & $\%$ \\
\hline Se eu conhecesse algum ponto de coleta de REEE, descartaria meus REEE lá. & 87 \\
\hline Mesmo que eu conhecesse algum ponto de coleta de REEE, não descartaria meus REEE lá. & 13 \\
\hline
\end{tabular}

Fonte: Dados da pesquisa.

Quanto à disposição em efetuar o descarte de REEE corretamente em pontos de coleta, os respondentes que disseram não conhecer pontos de coleta, afirmaram, em sua maioria, que se deslocariam para descartar os REEE até o ponto de coleta mais próximo. Entretanto, tal postura não se mostrou unânime, uma vez que uma parcela de $13 \%$ dos respondentes se mostraram indiferentes ao conhecimento de pontos de coleta para descarte dos REEE, o que reforça a necessidade de políticas públicas relacionadas à educação ambiental nas residências.

Finalizando, todos os respondentes disseram em entrevista que consideram necessária uma conduta de esclarecimentos por parte do poder público quanto à forma correta de descarte, bem como as consequências do descarte incorreto para o meio ambiente e para a saúde humana. Entretanto, o mesmo comportamento estático identificado em empresas e consumidores nos estudos de Araújo (2013) e na descrição quantitativa de Rodrigues, Gunther e Boscov (2015) são externados nesse estudo, uma vez que desponta, na perspectiva do consumidor final, um discurso de consciência ambiental antagônico às práticas realizadas.

\section{CONSIDERAÇÕES FINAIS}

Os achados descritos na pesquisa apontam para uma melhor compreensão e diagnóstico do processo de destinação de REEE na perspectiva do consumidor final do município de Vilhena/RO, sendo este, o ator inicial da logística reversa estabelecida pela PNRS. A consciência ambiental declarada dos consumidores e suas práticas sustentáveis, diagnosticada naquele município, de aproximadamente 100.000 habitantes, não se revelou distante dos estudos apresentados em regiões metropolitanas, como Manaus/AM (ARAÚJO, 2013) e São Paulo/SP (RODRIGUES; GUNTHER; BOSCOV, 2015).

Foi possível perceber que, embora haja definição legal, por meio da PNRS e legislações correlatas, e conceitual do papel dos consumidores na logística reversa dos REEE, como nas pesquisas de Xavier e Carvalho (2014) e Pereira, Ferraz e Massaini (2014), esses atores ainda exercem sua responsabilidade de forma tímida e, muitas vezes, inerte, esperando que o poder público tome as iniciativas de viabilização, implantação, educação, divulgação, execução, regulação e fiscalização dos ciclos reversos pós-venda e pós-consumo, conforme indicado por Leite (2017).

No que tange ao diagnóstico da destinação dada aos REEE pelos consumidores finais de Vilhena/ RO, apurou-se que a maior parte dos REEE gerados entre os respondentes são de pequeno porte, o que 
não os torna menos importantes e perigosos para o meio ambiente e para a saúde humana. Constatou-se ainda a prática de retenção de REEE, em padrões acima do que foi apresentado nos estudos do Market Analysis; IDEC (2013), além do descarte de REEE no lixo comum, como as práticas mais recorrentes entre os cidadãos daquele município, embora estes tenham conhecimento de suas responsabilidades quanto ao descarte correto. A pesquisa mostrou ainda indícios de assimetria informacional, entre prefeitura e cidadãos, que pode ter como causa provável uma deficiente divulgação das políticas públicas implementadas e voltadas para o descarte de REEE em pontos de coleta espalhados pela cidade.

O nível de conscientização dos respondentes mostrou que estes entendem seu papel no processo de preservação do meio ambiente e no convívio sustentável em sociedade, porém, a educação ambiental é uma vertente ainda pouco explorada naquela cidade, uma vez que muitos munícipes desconhecem como podem gerenciar seus REEE de forma eficiente, bem como as consequências nocivas do descarte incorreto de REEE. Esse paradoxo coaduna com o comportamento relatado nos estudos de Araújo (2013) e Pereira, Ferraz e Massaini (2014).

A pesquisa limitou-se a estudar apenas a cidade de Vilhena, no estado de Rondônia. Assim, não se pode generalizar os resultados, uma vez que a amostra analisada não representa significativamente a região da Amazônia Ocidental. Embora a pesquisa tenha tomado estudos anteriores como referência (PEREIRA; FERRAZ; MASSAINI, 2014; RODRIGUES; GUNTHER; BOSCOV, 2015), a análise via estatística descritiva não abordou análises de cargas fatoriais e de correlação entre as variáveis identificadas nos resultados. Outra limitação, em função da escassez de recursos e tempo, se deu pela definição de uma amostra com margem de erro de 10\%, o que não invalida os resultados, porém os fragiliza. Ainda como limitação, o estudo apresenta dados da geração de REEE em Vilhena, sem, contudo, aprofundar a compreensão dos aspectos que originaram essa geração, como inviabilidade de manutenção de EEE, aspectos particulares da obsolescência programada, perceptiva ou funcional.

Recomenda-se a replicação deste estudo nas demais cidades do estado de Rondônia, bem como em outros municípios brasileiros de outras regiões, a fim de ampliar o quadro diagnóstico da situação do descarte de REEE, na perspectiva do consumidor final, bem como para fins de análises comparativas dos resultados alcançados neste estudo, apontando para a proposição de políticas públicas, e também de políticas empresariais, mais efetivas quanto à logística reversa dos REEE no Brasil. Além disso, caberia uma investigação sobre a destinação dada aos REEE a partir dos pontos de coleta, bem como sobre a viabilidade econômico-financeira da prática de mineração urbana descrita por Xavier e Lins (2018), bem como da criação de empresas ou cooperativas de recolhimento, triagem e/ou reciclagem destes resíduos nos municípios futuramente pesquisados, como é o caso da cidade de Vilhena. 


\section{REFERÊNCIAS}

ABDI. Agência Brasileira de Desenvolvimento Industrial. Logística reversa de equipamentos eletroeletrônicos: análise de viabilidade técnica e econômica. Brasília: ABDI-INVENTTA, 2013. Disponível em: < http://www.abdi.com.br/Estudo/Logistica\%20reversa\% 20de\%20residuos_.pdf>. Acesso em 10 ago. 2017.

APPELT, A. I.; PORTO, W. S.; PEDRO FILHO, F. S.; CARNEIRO, A. F.; COSTA, R. F. Electronic waste management and discard of technology. Proceedings... In: The 30th International Conference on Solid Waste Technology and Management. Philadelphia/PA - USA, 2015.

ARAÚJO, J. G. Análise do gerenciamento de resíduos de equipamentos eletroeletrônicos residenciais em Manaus-AM. Dissertação (Mestrado em Ciências do Ambiente e Sustentabilidade da Amazônia). Universidade Federal do Amazonas, Manaus/AM, 162f., UFAM, 2013.

BALDÉ, C.P., FORTI V., GRAY, V., KUEHR, R., STEGMANN, P. The Global E-waste Monitor - 2017: Quantities, Flows, and Resources. United Nations University (UNU), International Telecommunication Union (ITU) \& International Solid Waste Association (ISWA), Bonn/Geneva/ Vienna, 2017.

BARTHOLOMEU, D. B.; CAIXETA-FILHO, J. V. (orgs.). Logística ambiental de resíduos sólidos. São Paulo: Atlas, 2011.

BRASIL. Decreto $n^{\circ} 7.404$, de 23 de dezembro de 2010. Cria o Comitê Interministerial da Política Nacional de Resíduos Sólidos e o Comitê Orientador para a Implantação dos Sistemas de Logística Reversa, e dá outras providências. Diário Oficial [da] República Federativa do Brasil, Brasília, DF, 24 dez. 2010b. Seção 1, p. 1-6.

BRASIL. Lei n ${ }^{\circ}$ 12.305, de 2 de agosto de 2010. Institui a Política Nacional de Resíduos Sólidos; altera a Lei no9.605, de 12 de fevereiro de 1998; e dá outras providências. Diário Oficial [da] República Federativa do Brasil, Brasília, DF, 3 ago. 2010a. Seção 1, p. 3-7. BRASIL. Ministério do Meio Ambiente. Portaria MMA nº 464, de 30 de julho de 2019. Torna pública a abertura de processo de consulta pública da proposta de Acordo Setorial para a implantação de Sistema de Logística Reversa de Produtos Eletroeletrônicos de uso doméstico e seus componentes. Diário Oficial [da] República Federativa do Brasil, Brasília, DF, 31 jul. 2019. Seção 1, p. 72.

CAIADO, N.; GUARNIERI, P.; XAVIER, L. H.; CHAVES, G. L. D. A characterization of the Brazilian market of reverse logistic credits (RLC) and an analogy with the existing carbon credit market. Resources, Conservation and Recycling. v. 118, pp. 47-59, 2017.

CAO, J.; CHEN, Y.; SHI, B.; LU, B.; ZHANG, X.; YE, X.; ZHAI G.; ZHU, C.; ZHOU, G. WEEE recycling in Zhejiang Province, China: generation, treatment, and public awareness. Journal of Cleaner Production. v. 127, pp. 311-324, 2016.

EL FARO, O.; CALIA, R. C.; PAVAN, V. H. G. A logística reversa do lixo tecnológico: um estudo sobre a coleta do e -lixo em uma importante universidade brasileira. Revista de Gestão Social e Ambiental - RGSA, São Paulo, v. 6, n. 3, set/dez, 2013.

FERNANDES, M. S. Gestão do lixo eletrônico nas empresas lojas de informática nos municípios de Espigão d'Oeste e Pimenta Bueno/RO. Trabalho de Conclusão de Curso (Bacharelado em Administração). Universidade Federal de Rondônia, Cacoal/RO, 28f., UNIR, 2016. 
FLYGANSVAER, B.; DAHLSTROM, R.; NYGAARD, A. Exploring the pursuit of sustainability in reverse supply chains for electronics. Journal of Cleaner Production. v. 189, pp. 472-484, 2018. FORTI, V.; BALDÉ, C. P.; KUEHR, R. E-waste statistics: guidelines on classification, reporting and indicators. 2th edition. United Nations University, ViE - SCYCLE, Bonn, Germany, 2018. GOOGLE EARTH. Localização do município de Vilhena/RO. Disponível em: <https:// earth.google.com/web/@-12.85874096,-54.96375691,-1217.83377481a,5358802.188 45606d,35y,0h,0t,0r/data=CkoaSBJCCiUweDkzYjk2YTNkOTVkNTdhZmI6MHhlN2U2NDA2Nm M0MmQwNzAyGVhO5y-ZeynAIQ9GR82yEE7AKgdWaWxoZW5hGAIgAQ>. Acesso em 31 out. 2017.

GREENPEACE. Incineração não é a solução. Disponível em: <http://www.greenpeace.org/ brasil/ PageFiles/4918/factsheet_incineracao.pdf >. Acesso em: 10 set. 2017.

IBGE. Instituto Brasileiro de Geografia e Estatística. Vilhena: população estimada 2018. Disponível em: 〈https://cidades.ibge.gov.br/brasil/ro/vilhena/panorama>. Acesso em: 20 jul. 2019.

LAVEZ, N.; SOUZA, V. M.; LEITE, P. R. O papel da logística reversa no reaproveitamento do "lixo eletrônico": um estudo no setor de computadores. Revista de Gestão Social e Ambiental RGSA. São Paulo, v.5, n.1, p. 15-32, jan./abr., 2011.

LEITE, P. R. Glossário de logística reversa. 2019a. Disponível em <http://clrb476.wixsite. com/ clrb-log-reversa/glossario-de-logistica-reversa>. Acesso em 04 ago. 2019.

LEITE, P. R. Logística reversa: problemas e soluções. (Palestra). In: XXI Semana do Meio Ambiente. FIESP. São Paulo, 2019b. Disponível em <http://clrb476.wixsite.com/clrb-log-reversa/ glossario-de-logistica-reversa>. Acesso em 04 ago. 2019.

LEITE, P. R. Logística reversa: sustentabilidade e competitividade. 3. ed. São Paulo: SaraivaUni, 2017. LEONARD, A. A história das coisas: da natureza ao lixo, o que acontece com tudo que consumimos. Rio de Janeiro: Zahar, 2011.

LEONARD, A. Story of Stuff, Referenced and Annotated Script. Disponível em: <http://s. bsd.net/stuff/default/page/Downloads/MovieScripts/SoStuff_Annotated_Script.pdf >. Acesso em: 17 set. 2017.

LU, B.; LIU, J.; YANG, J.; LI, B. The environmental impact of technology innovation on WEEE management by Multi-Life Cycle Assessment. Journal of Cleaner Production. v. 89, pp. 148-158, 2015.

LUZ, B. (Org.). Economia Circular Holanda - Brasil: da teoria à prática. Rio de Janeiro: Exchange 4 Change Brasil, 2017.

MARKET ANALYSIS, Instituto de Pesquisa; IDEC, Instituto de Defesa do Consumidor. O Ciclo de vida dos eletroeletrônicos. 2013. Disponível em <http://marketanalysis.com.br/wp-content/ uploads/2014/08/20140128_IDEC_MarketAnalysis_CicloDeVidaEletroeletr\%C3\%B4nicosParaDivulga\%C3\%A7\%C3\%A3o.pdf >. Acesso em 08 ago. 2019.

PEREIRA, F. A. M.; FERRAZ, S. B.; MASSAINI, S. A. Dimensões de consciência dos consumidores no processo de reciclagem do lixo eletrônico (E-WASTE). Revista Gestão \& Tecnologia. Pedro Leopoldo, v. 14, n. 3, p. 177-202, set./dez., 2014.

PORTO, W. S.; SOUZA, J. A.; CAMPOS, K. S.; FREITAS, M. A. L. Gestão do descarte de resíduos eletroeletrônicos com foco na TI verde. Amazônia, Organizações e Sociedade - AOS. v.7, n.2, jul/ dez. 2018, p. 47-68. Disponível em: 〈http://revistas.unama.br/index.php/aos/article/view/907/pdf〉. Acesso em: 17 jun. 2018. 
RASIL. Lei n ${ }^{\circ} 11.445$, de 5 jan. 2007. Estabelece diretrizes básicas para o saneamento básico; altera as Leis $\mathrm{n}^{\mathrm{os}}$ 6.766, de 19 de dezembro de 1979, 8.036, de 11 de maio de 1990, 8.666, de 21 de junho de 1993, 8.987, de 13 de fevereiro de 1995; revoga a Lei no 6.528, de 11 de maio de 1978; e dá outras providências. Diário Oficial [da] República Federativa do Brasil, Brasília, DF, 8 jan. 2007. Retificado em 11 jan. 2007. Disponível em: <http://www. planalto.gov.br/ccivil_03/_ato20072010/2007/lei/111445.htm>. Acesso em: 10 set. 2017.

ROBINSON, B. H. E-waste: an assessment of global production and environmental impacts. Science of The Total Environment. 408(2), 2009.

RODRIGUES, A. C.; GUNTHER, W. M. R.; BOSCOV, M. E. G. Estimativa da geração de resíduos de equipamentos elétricos e eletrônicos de origem domiciliar: proposição de método e aplicação ao município de São Paulo, São Paulo, Brasil. Eng. Sanit. Ambient. Rio de Janeiro , v. 20, n. 3, p. 437-447, Set. 2015 . Disponível em <http://www.scielo.br/scielo. php?script=sci_ arttext\&pid=S1413-41522015000300437\&lng=en\&nrm=iso> . Acesso em 08 ago. 2019. http:// dx.doi.org/10.1590/S1413-41522015020000133701.

SENADO FEDERAL. Logística reversa envolve indústria, comércio e consumidor. Em Discussão! Ano 5, n. 22, set/2014. Disponível em: <https://www12.senado.leg.br/emdiscussa o/edicoes/ residuos-solidos/@@images/arquivo_pdf/>.Acesso em: 10 set. 2017.

SILVA, M. E.; BALBINO, D. P.; GÓMEZ, C. P. Consumo sustentável na base da pirâmide: Definindo papéis e obrigações para a efetivação do desenvolvimento sustentável. Revista de Gestão Social e Ambiental - RGSA. São Paulo, v. 5, n. 2, p.18-33, mai/ago., 2011.

SMITH M. Research methods in accounting. London: Sage, 2003.

SOUZA, G. F. Avaliação ambiental nas cooperativas de materiais recicláveis. Tese (Doutorado em Medicina Preventiva) - Faculdade de Medicina, Universidade de São Paulo, São Paulo, 2015. doi:10.11606/T.5.2015.tde-20052015-103437. Acesso em: 03 ago. 2019.

TANSKANEN, P. Management and recycling of electronic waste. Acta Materialia. v. 61. pp. 10011011, 2013.

UE. União Europeia. Diretiva 2012/19/UE do Parlamento Europeu e do Conselho de 04 de julho de 2012 para o lixo de equipamentos elétricos e eletrônicos (REEE). Jornal Oficial da União Europeia. Luxemburgo, v. 55, 24 Jul. 2012.

VAISHNAV, D., DIWAN, R. E-waste management: an overview. Recent Research in Science and Technology. (05), p. 92-97, 2013.

WIDMER, R.; OSWALD-KRAPF, H; SINHA-KHETRIWAL, D; SCHNELLMANN, M; BÖNI, H. Global perspectives on e-waste. Environmental Impact Assessment Review. 2005. v. 25, iss. 5, pp. 436 - 458. Disponível em: <https://ac.els-cdn.com/S019592550500046 6/1-s2.0-S0195925505000466-main.pdf?_tid=03bb10f8-c1c9-11e7-aeae-00000aab0f27 \&acdnat=1509845656_b55bce8eb562ffdba1e6699be6efc0ec >. Acesso em 10 set. 2017. XAVIER, L. H.; CARVALHO, T. C. M. B. Gestão de Resíduos Eletroeletrônicos: uma abordagem prática para a sustentabilidade. Rio de Janeiro: Elsevier, 2014.

XAVIER, L. H.; LINS, F. A. F. Mineração urbana de resíduos eletroeletrônicos: uma nova fronteira a explorar no Brasil. Brasil Mineral. n. 379. Signus. São Paulo/SP, Março, 2018. 